\title{
Ética do Gueto: Figuras do Mal em Canções de Rap Brasileiras e Norte-Americanas
}

Thiago Cazarim da Silva

DOI - 10.25160/v5i2.ga.3

\section{Introdução}

Neste artigo, gostaria de traçar alguns apontamentos sobre a construção de imagens do espaço urbano em canções de rap brasileiras e norte-americanas. As canções aqui elencadas permitem identificar a cidade tanto como constructo poético-narrativo quanto como locus interpelador que convoca os artistas urbanos a reflexões sobre seus valores éticos e modos de viver no caos da periferia. De modo geral, perpassa as produções brasileiras quanto as estadunidenses analisadas um mesmo signo, o do mal, seja como escolha retórica para caracterizar narrativamente um atributo do espaço citadino, seja ainda como personagem antagonista com a qual os rappers travam diferentes embates. A cidade, por sua vez, é tratada aqui não apenas como o cenário e o conteúdo dramático das canções de rap, mas, ela também, como personagem privilegiada.

Mas, ainda que estes elementos dramáticos sejam comuns às canções escolhidas, independente de pertencerem a contextos geográficos, históricos e socioculturais bastante distintos, é necessário adiantar que esta aproximação não tem a pretensão de produzir uma narrativa universal ou totalizante sobre o rap, como se não houvesse diferenças estilísticas (musicais, linguísticas, performáticas) significativas entre os artistas brasileiros e dos Estados Unidos. As aproximações feitas neste artigo, na verdade, só têm se tornado possíveis para mim na medida em que o rap é compreendido como cultura transnacional, ou seja, em contexto de diáspora (Guerreiro, 2010; Gilroy, 2012; Garcia, 2014). Além do suporte encontrado na literatura sobre o rap, parte das observações de campo de minha pesquisa de doutorado (em andamento) têm fornecido elementos que mostram que não apenas temporalmente, mas também geograficamente, algumas representações sobre a vida nas cidades, bem como signos artísticos, transitam de forma circular e são compartilhados entre Brasil e Estados Unidos, entre o presente e o passado recente - algo, aliás, que remete à própria técnica composicional de loop empregada por DJs na criação das bases musicais sobre as quais as letras de rap se desenvolvem.

Considerando então o rap como cultura mundial, partilhando seus signos, imagens, práticas e representações para além dos limites locais ou nacionais, proponho uma leitura transversal de canções dos rappers Paris, KRS-One e dos grupos Facção Central, Face da 
Morte, Racionais MC's e Thiagão e os Kamikazes do Gueto ${ }^{1}$. Como eixo de análise, destaco as diferentes formas pelas quais a identificação da existência do mal na trama urbana funciona tanto para caracterizar o espaço da cidade quanto como ocasião de reflexão ética para os rappers. A discussão se organiza, então, em quatro seções: (a) apresentação de conceitos concernentes ao movimento hip-hop (no qual se insere o rap) e à noção de ética empregada neste artigo; (b) as diferentes caracterizações da cidade-mal como cenário, tema e personagem das dramatizações das canções de rap; (c) a dimensão po-ética do rap como forma de produção de subjetividades; (d) o artifício retórico e dramático da caracterização que os rappers de si mesmos como "demônios rimadores", como tática de subversão da ideia de mal e como forma de contestação das representações hegemônicas das culturas das periferias. O objetivo deste percurso é, partindo do reconhecimento de elementos da dinâmica sociocultural que compõe o universo do rap, apresentar aos leitores as diferentes estratégias artísticas e de pensamento político e ético empregadas por rappers na difícil arte de viver pela arte em contextos de adversidade e intensa violência.

\section{Ética no gueto}

O hip-hop se forma historicamente como uma complexa imbricação de diferentes atores, ações e práticas artísticas e sociais. Surgido na década de 1970, aglutinou uma série de práticas artísticas urbanas dos guetos nova-iorquinos, nomeadamente o rap (contemplando seus dois elementos principais, o MC e o DJ), a break dance e o grafite, assim constituindo-se como manifestação poética, musical, corporal e gráfica. Apesar de estes quatro elementos já existirem mais ou menos independentes antes dos anos 70 e de o termo hip-hop ter sido creditado ao MC Love Bug Starski, o trabalho do DJ Afrika Bambaataa colaborou decisivamente para que o hip-hop se consolidasse no sentido mais amplo de cultura dos guetos nova-iorquinos, tal como apontam Rose (1994), Rosa (2006), Camargos (2015) e Fleury (2015). Ainda assim, podemos dizer que provavelmente o rap

\footnotetext{
${ }^{1}$ Este é um índice preciso de como o rap se constitui como cultura transnacional. Conforme indico mais adiante, a definição sociológica de gueto, segundo Loïc Wacquant (2008), não poderia ser aplicada de forma rigorosa à caracterização de formações urbanas como favelas ou para explicar a dinâmica própria das periferias das cidades brasileiras. No entanto, "gueto", mais que um conceito, circula no meio rapper como imaginário amplo capaz de abrigar as mais diferentes experiências urbanas marcadas pelas desigualdades econômicas, culturais e raciais. "Gueto" é, então, um índice que atravessa os limites locais - o que, por outro lado, não implica dizer que ele não seja ressignificado localmente. Assim mesmo, "gueto", muitas vezes marcado pelo mal, é um índice que permite o compartilhamento e a produção de sentidos sobre a cidade. É apenas por esta razão, e como recorte provisório de leitura escolhido para o escopo deste artigo, que opto aqui por usá-lo para abreviar a discussão sobre as relações entre formação geográfica das cidades contemporâneas (tendo, evidentemente, consciência dos limites teórico-analíticos de tal opção).
} 
tenha se consolidado como a mais forte referência da cultura hip-hop, sobretudo se levarmos em conta o papel da indústria fonográfica e dos meios de comunicação de massa na difusão deste gênero musical (Garcia, 2014; Rose, 1994).

Para compreender melhor o contexto social do desenvolvimento da cultura hiphop, cumpre retomar a descrição que Wacquant (2008) faz da própria ideia de gueto e da transformação pela qual os guetos norte-americanos passaram ao longo do século XX. Ao refazer a história dos guetos de judeus na Europa, Wacquant (2008) define como indispensáveis quatro características para a identificação de um gueto contemporâneo: estigma, delimitação geográfica, encapsulamento organizacional e coerção. Nesse sentido, o autor defende que apenas nos Estados Unidos podemos identificar a existência de guetos reais, que se distinguem de bairros étnicos sobretudo pela questão da restrição, por motivos raciais, de grupos sociais a determinadas áreas geográficas.

Uma importante transformação diz respeito ao modo como o aspecto de encapsulamento organizacional modificou-se a partir da década de 1970 nos guetos novaiorquinos. Inicialmente, referindo-se às redes de solidariedade e à economia independente criadas no interior dos bairros negros para compensar as diferentes formas de estigmatização, coerção e delimitação geográfica, o que se viu acontecer a partir da década de 1970 foi um esvaziamento das políticas públicas voltadas à população dos guetos, que teve como efeito direto seu despovoamento massivo com o consequente aumento da violência (pela escassez de serviços públicos e de empregos disponíveis) e o afrouxamento das relações interpessoais (já que famílias, separando-se umas das outras em busca de bairros com melhores condições de vida, não mais se encontravam e não podiam mais contar umas com as outras no cotidiano).

Por outro lado, Wacquant (2008) descreve que, além do efeito repressor dos guetos, podemos neles identificar a emergência de diversas formas de resistência. Segundo Garcia (2014, p. 21 - 22), o rap pode ser lido "como expressão artística do gênio popular e juvenil negro, uma prática de resistência que atualizaria o espírito africano na produção cultural", uma "linguagem musical que possibilita canais de expressão, sobretudo para a juventude marginalizada das classes trabalhadoras[,] que ao produzir ou consumir a música rap faz circular representações que questionam o imaginário social hegemônico". Em certa medida, então, a emergência do hip-hop teria constituído uma reação tanto aos princípios quanto aos efeitos das políticas de reurbanização do distrito nova-iorquino do Bronx, dentre outros fatores sociais, tais quais o desinvestimento estatal em serviços públicos, o racismo, o aumento da repressão policial como política contra o aumento da violência e da criminalidade, a falta de segurança e de perspectivas econômicas que não aquelas ligadas 
ao mercado das drogas, além do afrouxamento das relações interpessoais acompanhado do fortalecimento das gangues.

Ao relatar o modo pelo qual redirecionará suas ações pessoais e seu modo de vida, anteriormente marcados pela participação ativa na gangue Black Spades, Bambaataa (2007) descreve a motivação para a criação do hip-hop como tentativa de abertura a uma nova relação com a realidade em que vivia:

A vida era realmente uma batalha, gangues de rua e violência por todos os lados. Mas em meio a tudo isso, tínhamos por exemplo, grandes professores do Islã. Pessoas como Malcolm X e Louis Farrakan. Tínhamos o Partido dos Panteras Negras e Angela Davis. Tínhamos grandes cantores como James Brown, Aretha Franklin, Sly \& The Family Stone, Isley Brothers, John Lennon e tantos outros. Seja por meio de suas músicas ou de seus discursos, todos me ensinaram algo de bom. Algo que me ajudou a moldar minha mente de forma positiva e a me tirar do ócio e do crime, me levando a pensar em fazer algo pelo meu povo.

É clara a correlação entre pensamento, valores e ações: os ícones e produtos culturais permitem a elaboração de uma reflexão acerca de sua própria subjetividade, dos modos de agir no mundo e dos valores atribuídos a eles (positivos ou negativos). Deste modo, é imprescindível considerar um quinto elemento da cultura hip-hop, aquele que, nos dizeres de diversos artistas, promove a transformação pessoal de cada indivíduo e coletiva do povo negro e das periferias urbanas. Tal elemento é o que se chama de conhecimento.

Existe uma polissemia implicada na noção de conhecimento trazida pelos rappers e artistas do hip-hop que deve ser explicitada. Um dos sentidos deste termo refere-se à importância da apropriação de conhecimentos históricos sobre a história dos povos oprimidos, principalmente o das populações negras ao redor do mundo, como ferramenta importante na formação de estratégias de resistência política e transformação social (Black Soul, 2009; Botelhos, 2010; Arraes, 2015). Outro sentido diz respeito ao poder integrador do conhecimento: ele é o elemento capaz de aproximar diferentes manifestações culturais que funcionam também isoladamente como subculturas, a partir de um terreno comum de informações, valores e sentidos (Griot Urbano, 2015). Um terceiro sentido, que gostaria de enfatizar aqui, remete à vinculação entre prática artística, ação política e a constituição de formas de subjetividade. Ao definir o hip-hop como modo de resistir à violência, Bambaataa (Black Soul, 2007) não afirma simplesmente que os sujeitos, em relação a seus 
grupos identitários e à sociedade como um todo, acatam normas e valores de conduta dados; o que parece ser afirmado é que, para além do poder exercido pela lei e pelas forças repressivas e excludentes (valores negativos), é possível constituir-se a si mesmo como sujeito que busca ativamente maneiras de construir uma forma singular de agir e reagir ao conjunto de valores, condições, normas e códigos que constituem a sociedade e o tempo histórico que o atravessam.

Por essa razão, o conhecimento é esse exercício do sujeito em relação a si mesmo que resulta na produção singular de um modo de vida. Também por isso, podemos dizer que o modo como Bambaataa realizou a sedimentação do hip-hop em torno do conjunto música-poesia-dança-grafite representou, desde o início, a tentativa de constituir uma ética: segundo ele, o objetivo do hip-hop era sublimar a violência dos guetos, especialmente em relação às disputas territoriais de suas gangues, de forma a instituir uma nova forma de resistência política e de afirmar a cultura negra. Ou seja, a arte, sendo política, também era a busca por outra forma de existência. Por ética, aqui, entendemos a definição trazida por Castro (2009, p. 156) acerca do tratamento foucaultiano do tema:

[Foucault afirma que] "uma ação, para ser chamada 'moral' não deve reduzir-se a um ato ou a uma série de atos conformes a uma regra, uma lei ou um valor. Toda ação moral, na verdade, comporta uma relação com o real onde ela se realiza e uma relação com o código ao qual se refere. Porém ela implica também certa relação a si mesmo. Essa relação não é simplesmente 'conhecimento de si', mas a constituição de si como 'sujeito moral', na qual o indivíduo circunscreve a parte dele mesmo que constitui o objeto dessa prática moral de si mesmo. E, para fazê-lo, atua sobre si mesmo, empreende o conhecimento de si, se controla, se põe à prova, aperfeiçoa-se, se transforma" [...] O termo ética refere-se a todo esse domínio da constituição de si mesmo como sujeito moral.

O comentário de Judith Revel (2005, p. 82) permite ainda compreender o tipo de relação que os rappers desenvolvem consigo mesmos diante dos dilemas da vida urbana:

O termo "subjetivação" designa, para Foucault, um processo pelo qual se obtém a constituição de um sujeito, ou, mais exatamente, de uma subjetividade. Os "modos de subjetivação" ou "processos de subjetivação" do ser humano correspondem, na realidade, a dois tipos de análise: de um 
lado, os modos de objetivação que transformam seres humanos em sujeitos - o que significa que há somente sujeitos objetivados e que os modos de subjetivação são, nesse sentido, práticas de objetivação; de outro lado, a maneira pela qual a relação consigo, por meio de um certo número de técnicas, permite constituir-se como sujeito de sua própria existência.

Grosso modo, podemos afirmar que a produção de canções, estilos de dança e o grafite corresponde ao que esta autora denomina lado objetivado da produção de subjetividade: são os produtos, como formas materiais concretas de uma relação simbólica, que permitem ao sujeito tematizar e construir aquilo que configura sua peculiaridade no mundo. Em suma: o rap é, ao lado da dança e do grafite, uma técnica eficaz que permite aos sujeitos retomarem os desafios postos pelo cotidiano e que, conforme são aceitos ou rejeitados, se afirmam como ocasiões de exercício das condutas e dos valores nelas envolvidos.

Este aspecto exige considerar o rap como instrumento, técnica e exercício que se pratica diante de uma espécie de prova de fogo, a saber, a extrema violência e subalternização colocadas pela vida urbana. Ora, essa prova traz consigo, desde o princípio, a marca do mal: seja como avaliação da conduta de outrem (Racionais MC's, $2007^{2}$ ), seja ainda em relação às diversas personificações do mal (Face da Morte, 2011) seja em relação à cidade como lugar em que males ocorrem e que está associada à falta de ordem e ao caos (Testemunha Ocular, 2013³). Como afirma Joy James (2006, p. 84) ao comentar sobre a relação entre o rap e as múltiplas formas de violência, "os artistas de rap criam arte para amaldiçoar inimigos externos (polícia, gangues rivais) ou internos (mulheres, gays), com o objetivo de desviar o mal e criar novos poderes".

É então contra o mal e os males, que habitam e ocupam espaços na vida, no pensamento e na urbe, e que ganham corpo em personæ e afetos, que a poesia e a música irão se dirigir, colocando o sujeito numa relação de provação à qual ele responde e que correlativamente lhe serve como forma de criar sua forma de agir no mundo. Por isso, apresento a seguir alguns exemplos de que maneira a questão do mal é representada em

\footnotetext{
2 "Enfim, quero vencer sem pilantrar com ninguém".

${ }^{3}$ O refrão desta canção, que repete o título Goiânia em caos, traz uma clara associação entre problemas urbanos e o caos da vida na periferia, sem deixar de colocar a importância das ações dos sujeitos que sofrem com os problemas, tal como pode ser observado no início e no fim do trecho destacado: "Se olharmos por um lado, meia culpa é nossa,/ pois escolhemos um governo que é uma bosta./ O povo tá na rua, não está se mexendo,/ mesmo vendo tudo isso que está acontecendo./ Drogas e mortes na periferia, moleques abandonados, guerras de torcidas./ Pode apostar que temos atitude, vamos solucionar/ todos esses problemas que um dia podem te matar./ É tudo uma questão de conscientização/ que está na rua como uma espécie de mutirão./ Não aguento mais ver toda essa violência/ e todas essas mortes acontecendo em sequência."
} 
canções de rap, e de que modo ela, afirmando sua premência, é capaz de colocar em jogo uma série de ações que se desenrolam no domínio tríplice da ética, da política e da arte.

\section{Cidade-inferno e demônios urbanos}

Uma pergunta pode ajudar a introduzir a questão: que tipo de apresentação os rappers fazem da cidade que a toma, consequentemente, como locus próprio de diversas formas do mal? A literatura sobre o rap e o hip-hop indica que a violência urbana, sobretudo aquela produzida pelos agentes do Estado, torna a cidade o lugar por excelência do surgimento do sofrimento, da exclusão, da minoração e do veto aos direitos humanos e ao exercício da cidadania. Além dos quatro processos levantados por Wacquant (2008) que levam à formação de guetos estadunidenses, podemos ainda retomar as discussões de Corlett (2006) e Kelly (2006) para compreender as relações do rap com os males urbanos. Enquanto o primeiro autor retoma a canção What would you do? do rapper Paris para lembrar que "ele lança um desafio moral a todos os cidadãos americanos para dizer ao governo que nós não permitiremos que ele cometa maldades ao redor do mundo por nenhuma razão" (Corlett, 2006, p. 159, grifo do autor), Kelly (2006, p. 187) demonstra como a política de guerra às drogas dos Estados Unidos atrela o mal ("os males do crack") à população negra, gerando um encarceramento massivo resultante de opressão estatal de cunho racial:

A disparidade racial pode ser explicada por uma concentração da aplicação da lei contra drogas nas comunidades urbanas, minoritárias, nas quais o crack, a forma mais barata de cocaína, é mais prevalecente sobre a cocaína em pó. A mídia também exagerou os "males" do crack quando o governo lançou sua "guerra contra as drogas" na década de 1980. O resultado é o que [o] Human Rights Watch descreveu como "um indefensável diferencial no sistema de sentenciar que se torna desapropriado à luz de seu impacto racial".

É na canção de Dead Prez que Kelly (2006, p. 186) identifica o elo entre a descrição da cidade como espaço pleno de males com os processos sociais que fazem da vida uma prisão: 
Quando as pessoas são pobres, estão desempregadas, sem esperança e são submetidas à violência das ruas e ao abuso policial, a prisão torna-se a última coisa a temer, como Dead Prez deixa claro em "Behind Enemy Lines" [Por trás das linhas inimigas]:

Você não tem de estar trancafiado para estar na prisão

Olhe como estamos vivendo

30 mil negros por dia, na prisão, na mesma rotina

Eles nos colocam em uma caixa, igual à nossa vida no quarteirão.

Vigilantismo, perseguição racista, ausência de oportunidades, isolamento social: todos estes aspectos são as formas pelas quais o Estado e a sociedade de forma mais ampla exercem o mal contra o qual Corlett (2006) e Paris nos dizem ser necessário combater. É, assim, a forma segregadora de urbanização e da ação estatal que permite o surgimento, o desenvolvimento e a persistência dos males urbanos. Mas essa relação é complexa, como o caso da guerra às drogas parece indicar. Por um lado, o mal é um dispositivo políticomidiático altamente eficaz de controle social (Kelly, 2006; Wacquant, 2008): uma vez realizada a associação entre uso de drogas e mal urbano, o Estado mascara os interesses raciais e socioeconômicos de controle social por meio de uma política pública que promete à população em geral uma resposta eficaz contra a violência urbana. Por outro lado, a população dos guetos entende a ação do Estado como mal ao lado dos demais males que o Estado promete resolver por meio da repressão. Se o Estado e os meios de comunicação identificam no uso de drogas um tipo de mal (social, urbano etc.), em contrapartida, tal diagnóstico desencadeia uma série de males (racismo, violência estatal, encarceramento em massa, aprofundamento da segregação social) que serão vividos pela população da periferia.

Desta forma, a cidade é vivida e representada como locus infernal, tal como afirmado na canção Só Monstro, de Thiagão e os Kamikazes do Gueto (2009): “É cruel, a vida não é doce igual ao mel,/ falar pro filho não roubar, não matar que não vai pro céu./ Que céu? A gente vive é no inferno, tio". Uma representação semelhante aparece na canção de Naughty By Nature, Everything is gonna be alright, comentada por Lawson (2006, p. 166): "Dizer alguma coisa positiva? Bem, positivo não é o lugar onde eu morei/ Eu morei a um quarteirão do inferno ocidental", na qual o lugar em que se vive figura como prelúdio, fronteira ou portal do inferno.

A cidade é ainda descrita, em Sociedade quase alternativa, do grupo goiano Testemunha Ocular, como local caótico e aberrante, que faz com que as pessoas se vejam 
"sobrevivendo em meio às ruínas da Babilônia" (Testemunha Ocular, 2015). Porém, é importante observar que as canções de Naughty By Nature, Testemunha Ocular e Thiagão e os Kamikazes do Gueto indicam que a cidade é um espaço heterogêneo pela forma como os males nela se distribuem. Afinal, se "na quebrada só [tem] monstro,/ e no gueto, só monstro,/ e no rap, só monstro,/ e no crime, só monstro,/ os menor, só monstro,/ na cadeia, só monstro" (Thiagão e os Kamikazes do Gueto, 2009), o inferno parece estar mais perto de uns do que de outros na cidade: pois quem efetivamente mora "a um quarteirão do inferno ocidental" senão os doentes e demais vítimas da sociedade capitalista de que falam Naughty By Nature e Testemunha Ocular?

A associação da monstruosidade da cidade-Babel ao mal e ao inferno fica evidente ainda em Escape from Babylon, (Paris, 1990a). Retomando a crítica à disseminação das drogas entre a população negra/periférica como mal urbano, Paris (1990a) alerta:

\section{Young brothers just don't realize \\ Cocaine's the plan, the devil derived \\ Produced and let loose to youth for profit \\ Fake so-called negroes won't stop it \\ Witness lies fed straight to the brother man \\ Hopes are lost to the malevolent gameplan ${ }^{4}$}

A cidade, essa forma contemporânea da Babilônia, é o lugar onde o inferno se materializa e toma corpo em figuras diabólicas. De todo modo, a quem, concretamente, a crítica de Paris se volta quando evoca o imaginário sobre o demônio? Se o demônio é o conspirador que lança mão de uma "estratégia malévola", se ele é que dissemina a cocaína entre os jovens negros para com ela lucrar, quem é ele afinal? Como hipótese, gostaria de indicar que são os agentes estatais que os rappers identificam como demônios urbanos. Essa chave de leitura se baseia em dois pontos.

Em 1996, o jornalista investigativo Gary Webb lança uma série de reportagens intitulada Dark Alliance, que resulta num livro de mesmo título (Webb, 1998). O argumento geral deste trabalho é mostrar como a política estadunidense de guerra às drogas contribuiu intencionalmente com o mercado do narcotráfico, inclusive com a participação da CIA na disseminação do crack entre a população negra dos Estados Unidos. Neste ponto, não é demais lembrar a data do lançamento de Escape from Babylon: 1990. Por isso,

\footnotetext{
4 Tradução aproximada: "Os jovens manos não percebem [que a]/ Cocaína é o plano [que] o demônio sintetizou/ Produziu e deixou correr solto pra lucrar/ Os pretos de fachada não vão parar isso/ Testemunham mentiras lançadas direto para os irmãos/ Esperanças são perdidas para a estratégia malévola ".
} 
parece que a denúncia musical de Paris antecipa a investigação jornalística de Webb, criando um terreno discursivo comum que permite aproximar a forma simbólica demoníaca presente na canção de Paris com a ação dos agentes governamentais apontados explicitamente em Dark Alliance.

Além disso, como segundo ponto, a associação direta entre personificação do mal (demônio, diabo) e agentes do Estado policiais ocorre em canções como Lado B da Farda, do grupo Face da Morte (2011):

Dizem que o preto é pior, mas o branco não se salva.

Lagartinhos do sistema é isso que eles são,

Não compreendem que estão na mesma situação.

Não são da classe alta, não são ricos, nada disso,

São gente pobre igual a nós, só não entenderam isso

[...]

Mas quando vestem a farda pensam que são o Diabo

[...]

[Refrão]

Clack, clack

- Filho da puta, vai, põe a mão na nuca

Clack, clack: é o Diabo que desfila na rua

Tribunal de rua na hora da cena;

Simplesmente pobres lagartinhos do sistema.

Clack, clack

- Filho da puta, vai, põe a mão na nuca

Clack, clack: é o Diabo que desfila na rua

A viatura tá chegando, a molecada sai correndo

com medo de apanhar, já conhecem o veneno

[...]

Se [os policiais] só cumprissem a lei ficaria tudo bem,

Mas eles pensam que têm algum poder do além

Essa interpretação, enfim, deve levar em conta os versos do próprio Paris (1990), em The 
Devil made do it, nos quais o diabo é descrito como aquele que encontra prazer na truculência e na gratuidade da violência - o que nem de longe é difícil associar à atuação das forças policiais: "Beware the beast man/ for he is the Devil's pawn/ He kills for sport, or lust or greed/ Yea, he will murder his brother to possess his brother's land/ Shun him, for he is the Harbinger of death" ${ }^{\prime 5}$.

\section{O hip-hop como tecnologia de subjetivação: po-ética urbana}

Para além do mal materializado espacialmente, presente em ações concretas (violência, segregação, racismo, pobreza) e personificado em formas aberrantes ("monstros") e diabólicas, outras formas de mal, mais incorpóreas - e nem por isso menos atuantes -, parecem afetar a vida no inferno urbano. Vejamos, então, como a proximidade geográfica e cotidiana com as formas urbanas do mal se impõem como desafios éticos para os artistas do hip-hop.

A rotina do monstruoso, com todos os impactos que pode ter sobre as formas de vida na cidade, não resulta em respostas iguais da parte de todos os sujeitos que a habitam. Se em Atropelo, do Testemunha Ocular (2015), a própria vida é descrita como monstruosa, em Sociedade Alternativa, o mesmo Testemunha Ocular (2015) aposta que a cidade-“Babilônia cairá". Isso significa, de início, que existe uma crença que, ao diabólico estatal, aos males urbanos e à desordem da vida cotidiana da periferia provocada pela ordem social, é possível se opor e resistir. No entanto, essa resistência ao mal também não é assegurada e nem se forma de maneira espontânea ou obrigatória. Não é demais retomar a mensagem dura dos versos de Só monstro (2009): “do que que adianta eu falar pros moleque não roubar, não traficar,/ se a necessidade bate à porta/ [...]/É foda, diz pra mim em quem se espelhar,/ no pai que serra pinga ou no patrão de Golf e AK".

O mesmo tipo de mensagem aparece na forma de diálogo em outra canção de Thiagão e os Kamikazes do Gueto (2012), Na fé de Deus - Joga os Plaquê:

- Ô, Jão, tá embaçado, tá osso, cruel

Vocês tudo na gozolândia e eu pagando aluguel

\footnotetext{
${ }^{5}$ Tradução aproximada: “Cuidado com o homem-besta/ pois ele é o peão do Demônio/ Ele mata por esporte, ou lascívia ou ganância/ Sim, ele matará seu irmão para se apropriar da terra de seu irmão/ Desvie dele, pois ele é o Mensageiro da morte".
} 
Ô, primão, salva eu, arma uns corre pra mim, também quero la plata, as verde, os blim-blim, Mas como é que eu vou ter se eu num quero ripá, também num tenho muita disposição pra trampar Será que o governo num ajuda nóis um pouco mais? Aí sim, sangue bom, eu ia sonhar com a paz.

- Sem choradeira, rapaz, vai buscar, corre atrás, ninguém tem dó de você e você sonhando com a paz Que paz, que nada: é rajada na cara dos bico.

Por isso, é que a mesma canção afirma ainda que "É só monstrão/ No gueto a mulecada puxa o cão", mostrando que "o cão" (no sentido popular de diabo) acaba se constituindo não só como influência, mas estabelecendo uma relação de filiação em relação àqueles que não dispõem de referências melhores (inclusive familiares, já que o "primão", como vínculo familiar próximo com mais bens materiais e sucesso de vida, não oferece muita ajuda a quem lhe pede $)^{6}$. Parece, desta maneira, que uma das opções que se mostram possíveis e viáveis a quem se vê confrontado com horizontes limitados é a reprodução da violência e a adesão à criminalidade.

Longe de ser a prova decisiva de um determinismo sociológico, o que estes exemplos apontam é que os dilemas postos pelos males urbanos definem a cidade como campo a ser disputado pelas diferentes práticas que constituem sua dinâmica. Se a vida é dura e marcada pelo mal, este em contrapartida não é uma sentença inexorável, mas figura como questionamento que coloca os sujeitos diante da necessidade de definir suas ações diante do mal. Em outros termos, a cidade sob o signo do mal abre cena de interpelação, no sentido de Judith Butler (2015). Se a cidade emerge como marcada inexoravelmente pela desigualdade, pela violência, pelo racismo, pela ausência de oportunidades econômicas, ela se coloca diante de seus habitantes como uma interrogação, e não como uma sentença derradeira. Desta forma, é que poderíamos ler os versos de $A$ vida é desafio, do grupo Racionais MC's (2016): “A vida não é o problema; é batalha, é desafio/ Cada obstáculo é uma lição, eu anuncio". E se a vida é feita de desafio e luta, e se isso não constitui exatamente um problema, nem por isso deixa de ser um questionamento ético aberto que coloca em jogo a formação de condutas e dos valores a ela atrelados: “Então

\footnotetext{
${ }^{6}$ Em The Devil made me do it, Paris (1990b) não só diz que o diabo (o policial, o supremacismo branco) levam às más ações; o diabo produz o sujeito: "The Devil made me".
} 
segura, hã, aperte o cinto, se segura/ A vida é tipo um jogo, viu só?, uma disputa/ Porém, bem melhor quem tiver boa conduta/ Que a vida num é só festa, não, n'é só muvuca" (Testemunha Ocular, 2015).

A interpelação sofrida pelos rappers nos diferentes momentos e instâncias em que precisam dar uma narrativa de si, de suas vidas e ações, constituirá um dispositivo complexo em que se produzem e articular sentidos sobre lugar e um horizonte aberto para a produção de subjetividades. Longe de ser um lugar de uma tranquila contemplação metafísica, a canção de rap é um espaço simbólico de intensa luta contra o mal que pode habitar tanto exteriormente a cidade como as mentes e desejos dos rappers, donde a temática do domínio da própria subjetividade ganha relevância para os rappers que definem seu trabalho numa vertente de crítica ou conscientização. Shusterman (2006, p. 74) apresenta este aspecto ao definir o rap como

estratégia oferecida pelos rappers do conhecimento como KRS-One e Guru para a superação da violência destrutiva por meio do conhecimento; uma violência sobre si mesmo que fortalece o eu sem ferir os outros. Repetindo a mensagem darwiniana de que "tudo na natureza rege pela porrada", a canção de KRS-One, "Health, Wealth, Self" [Saúde, riqueza, eu] (KRS$O N E$ ) defende a autopercepção por meio do rígido autocontrole. A faixa "Breath Control" [Controle da respiração] (Edutainment) relaciona o tema do autocontrole às exigências vocais da própria arte do rap; enquanto sua canção mais recente "Squash All Beef" [Acabe com todo o rancor] (KRS$O N E)$, liga seu disciplinado vegetarianismo ao tema geral de parar a violência, insistindo que seus ouvintes sejam pelo menos "vegetarianos mentais", dirigindo sua energia não para atacar os outros, mas como um eficiente autocontrole e a busca por conhecimento [...]. Jeru de Damaja (em 'Ain't the Devi Happy?' [O diabo não está feliz?], de The Sun Rises in the East] é ainda mais claro quanto ao modo como a busca pelo poder do autoconhecimento e autocontrole requer um ataque violento aos desejos destrutivos da pessoa: "Você tem de descobrir o poder do eu/ Conhece-te a ti mesmo/ Encontra-te/ O ódio em ti/ Mata em ti".

A eficácia do autocontrole contra as más ações prometida pelo verso "Discipline, if you're listenin', defeats the cops"7 de You go on?, de KRS-One (2004d) é seguida imediatamente pela

\footnotetext{
${ }^{7}$ Tradução aproximada: “A disciplina, se você estiver escutando, derrota os tiras”.
} 
rejeição da ignorância como sua correlata necessária: "Fuck the dumb shit" . Consequentemente, é necessária uma disciplina interior, como resposta ao dilema ético posto pelos males urbanos, que resulte na adoção de condutas capazes de afastar a ignorância e forjar armas eficazes de luta social. De que maneira, então, essa disciplina se forma?

KRS-One pode dar algumas pistas sobre esta questão. Em Everybody Rise (2004a), ouvimos logo de início: "Learn the techniques of KRS/ [...] real hip-hop [...]/ so you don't have to worry and doubt". KRS, acrônimo para "Knowledge Reigns Supreme" (O Conhecimento Reina Supremo), indica que o conhecimento exigido para o autodomínio possui técnicas que podem ser aprendidas. Além disso, indica que o conhecimento se atrela ao hip-hop real, verdadeiro, tal como em Illegal business (KRS-One, 2004b): "I'm not rhymin' for a Bentley or a house this plush/I spit for the conscious [...]/ Time's up, time to open that mind up"10.

Neste ponto, podemos precisar melhor a aproximação entre rap, ética e a questão do mal. Não se trata de recair na crença de que o mundo é povoado por entes maléficos sobrenaturais ou de simplesmente assumir um ponto de vista maniqueísta ou fatalista sobre a presença do mal na cidade. Se há mal na cidade e se é possível inclusive personificá-lo, isso não se deve simplesmente a uma ética da des/obediência irrefletida de um conjunto rígido de valores, leis ou normas. Também não é como moralismo que o tema do mal se apresenta: se talvez devamos admitir como binário o sistema que classifica os homens entre o bem e o mal e os pensamentos entre positivos e negativos, isso não se dá em resposta a uma lei moral transcendental ou a um imperativo genérico e totalizador aceito como norma social incontornável; ele emerge, acima de tudo, da premência da vida concreta, dos dilemas ao mesmo tempo íntimos e públicos que colocam os sujeitos diante do desejo de uma vida outra. Portanto, se o mal está distribuído pela cidade, se ele se personifica na polícia e se seus correlatos mais recorrentes são a ignorância e a brutalidade, ocorre que a exigência de autocontrole pessoal, com todas as técnicas que lhe correspondem, é a maneira pela qual se torna possível sair da cercania do mal - enquanto fenômeno urbano - e dos maus - enquanto personificações deste último; é, ainda, um modo melhor de produzir a existência e o pensamento.

Especificamente sobre a questão das técnicas que se empregam nesse exercício

\footnotetext{
${ }^{8}$ Trad. aprox.: "Foda-se a merda estúpida".

9 Trad. aprox..: "Aprenda as técnicas de KRS/ [...] hip-hop de verdade [...]/ assim você não precisa se preocupar e duvidar".

${ }^{10}$ Trad. aprox.: "Eu não tô rimando por um Bentley ou por uma casa de luxo/ Eu lanço [a rima] para os conscientes [...]/ O tempo acabou, é tempo de abrir essa mente".
} 
subjetivo, é bastante ilustrativo o comentário do MC Monge (Griot Urbano, 2016b) sobre o processo de abandono das gangues criminais dos guetos que foi acompanhado, em muitos casos, pelo surgimento das chamadas crews, ou seja, grupos artísticos do movimento hiphop. O que vale destacar desta fala é a constatação de que a prática das batalhas artísticas (de rimas, dança, grafite e discotecagem) representa simultaneamente aprimoramento técnico-artístico e modo de sublimar a agressividade, a violência e a dureza da vida nos guetos em formas expressivas. Em outro vídeo (Griot Urbano, 2016a), Monge advoga explicitamente pela compreensão das expressões do hip-hop como tecnologias, por meio das seguintes caracterizações:

I) O hip-hop apresenta em comum com a ideia de tecnologia o fato de possuir técnicas, produtos e processos desenvolvidos com o objetivo de resolver problemas;

II) O hip-hop é uma tecnologia, já que, como as demais tecnologias, é um tipo de saber sistematizado de uma forma de vida, que pode ainda ser transmitido e disseminado.

O que é ainda mais significativo neste último vídeo é a associação entre autoconhecimento, autoestima e arte. Se levarmos em conta os versos de Goiânia em Caos (Testemunha Ocular, 2013) - "Pode apostar que temos atitude, vamos solucionar/ todos esses problemas que um dia podem te matar/ É tudo uma questão de conscientização" -, poderemos então entender não apenas a exigência de KRS-One de dominar as técnicas do verdadeiro hip-hop, mas ainda descrever propriamente a prática das disputas (batalhas) artísticas como aquilo que Monge indica como poder do hip-hop de mudar a conduta (postura) e as formas de ação diante do mundo. Seja do lado especificamente artístico, da teknê rapper, seja do lado da evolução pessoal no seio da comunidade e da sociedade, o sujeito aceita o desafio de se colocar à prova, de, num processo contínuo de aprimoramento pessoal por meio das artes do corpo, do som, do desenho, da palavra e do pensamento, produzir um modo seu de se guiar no mundo infernal e de manter-se à distância, para melhor enfrentá-los, daqueles que serão seus inimigos declarados: os demônios personificados e os males dos pensamentos negativos, frutos da ignorância e que reproduzem o mal que julgam confrontar. 


\section{“Demônios rimadores": confundir para dominar (ou ao menos resistir...)}

Vânia Olária (2012, p. 87), ao reproduzir trechos de entrevistas realizadas para integrar sua pesquisa de mestrado sobre o hip-hop em contextos escolares, traz uma informação importante: Beicim, um dos entrevistados, "considera que as pessoas em geral, assim como ele, gostariam de ter um pacto com alguma coisa e que o dele é com 'Deus, o todopoderoso'". Essa invocação de figuras divinas - seja o Deus cristão, seja Alá ou Krishna é, aliás, bastante frequente, especialmente se considerarmos que o rap, como arte da palavra, é tratado muitas vezes como dom, e como dom divino (cf. A vingança, Testemunha Ocular, 2015; Olária, 2012).

Paralelamente a isso, porém, é importante recuperar a ideia de que o conhecimento trazido pelo rap e pelo hip-hop "não se aprende na escola" (cf. Biografia, Testemunha Ocular, 2015). Não quero polemizar aqui a proposta de pesquisa de Olária (2012), mas somente indicar como o conhecimento - a arma forjada contra as formas de mal urbano não é o maná divino descido do céu, um presente transcendente, mas uma relação imanente de conquista de si e da verdade. Essa relação de imanência fica ainda mais evidente no verso de Freestyle Ministry, de KRS-One (2004b): “inner divinity to change society"11, de onde se infere que o poder de transformação não vem do além, mas do trabalho do sujeito sobre si mesmo.

Como afirmei anteriormente, o sistema de valorações e descrições dos rappers opera num estrato consideravelmente binário, o que permite compreender, inclusive, a necessidade de apelo à ideia de dom (divino) para explicar aquilo que somente os rappers, por meios que lhes são próprios, são capazes de produzir e desenvolver. O descompasso aparente entre as tecnologias das artes de expressar e de se dominar, de um lado, e a ambiguidade das caracterizações que se faz desse trabalho (ora imanentes à vida e à força interior dos sujeitos, ora tributárias de forças divinas exteriores), de outro lado, não pode ofuscar uma das formas mais provocativas de saber sobre si produzidas pelos rappers. Ela diz respeito à subversão da categoria "demônio", desatrelada da percepção do outro e agora utilizada como forma de conhecimento de si, tal como em Sei que os porcos querem meu caixão, do grupo Facção Central (2007, grifo meu): “Não deram faculdade pra eu me formar doutor/ Então a rua me transformou no demônio rimador". É em torno deste último ponto que gostaria de encerrar a presente discussão.

A temática do street knowledge, que KRS-One identifica como o quinto elemento do hip-hop (Griot Urbano, 2015), define para o rapper um lugar inusitado, ao menos do ponto

\footnotetext{
11 "Divindade interior para mudar a sociedade".
} 
de vista do Estado e do capitalismo: o lugar da sabedoria e da arte de bem argumentar (Griot Urbano, 2016a). Monge (Griot Urbano, 2015) afirma de mesmo modo que a capacidade de argumentar, de se expressar por meio das artes e de criar um estilo singular de falar e se vestir constituem uma ameaça ao Estado e à ordem vigente, que, por sua vez, tendem a responder com brutalidade ao que não compreendem. Ser, pensar e agir são formas, pois, de confundir o Estado - e é esse aspecto, o do poder de causar confusão, de responder à violência repressora com a impossibilidade de se submeter à uma ordem totalizadora, que parece se relacionar com a expressão "demônio rimador".

Se há a recuperação da figura demoníaca e a associação desta com a ideia de confusão do pensamento - assim como no caso do demônio-polícia e do demônio-Estado, que planta a divisão e a ignorância entre os jovens negros, corrompendo-os para o mundo do tráfico e da violência -, devemos lembrar também que o sentido da identificação de si e do outro como demoníacos é bastante diferente. Enquanto o outro (seja do ponto de vista do Estado, seja do ponto de vista dos rappers) é sempre visto como mal, e daí pensado como demoníaco, a descrição que os rappers eventualmente fazem de si mesmos como demoníacos, partilhando da ideia de demônio como aquele capaz de instituir a desordem e a confusão, assume o sentido da forma de resistir à repressão, ao controle social e à imposição de normas de conduta. Não se trata simplesmente de responder com desordem à desordem social, já que, como discutimos neste artigo, o rap pode representar uma tentativa de evolução, superação e reação positiva ao abandono sistemático e crônico do Estado. Mas também é preciso compreender que o simples fato de negar ao Estado a possibilidade de dominar e definir completamente o que constitui a subjetividade da população negra e periférica das cidades já constitui um processo de rejeição da ordem, ou melhor, de certo tipo de ordem social.

O poder de transmutar a agressividade em formas artísticas que permitem escapar do inferno urbano mantém nos rappers, vivas e abertas, diversas chagas do mal - a ponto de Monge (Griot Urbano, 2016b) afirmar como a fachada de "marra" durante as batalhas artísticas cumpre o papel importante de autoafirmação diante do outro e do Estado. Se essa postura fechada, dura e defensiva parece derivar do impacto dos males sociais sobre a vida no gueto, a afirmação de si como demônio capaz de desestabilizar as promessas de segurança para a população rica e branca por meio do rap faz da arte da periferia a possibilidade de ser a força que engana os próprios enganadores, que confunde aqueles que vieram plantar a discórdia e a escravidão das mentes.

E se ainda é possível praticar o mal entre iguais, como nos lembra o Testemunha Ocular em Olho Gordo (2015) - canção que termina com uma risada típica de um Exu -, e 
se, como afirma Mc Pherson (2006), talvez o rap não seja revolucionário, assim mesmo a capacidade interior de bloquear a ação de outrem sobre si, que requer o domínio de um vasto repertório de técnicas (de argumentação, artísticas, de autocontrole etc.), continue sendo uma das formas mais eficazes de resistir ao mal disperso na cidade. Não somente ao mal genérico, informe, mas ao inferno em que a cidade se converte, que, se nem sempre está a um quarteirão de distância, talvez esteja à espreita de cada um, a todo instante em que é necessário narrar que tipo de subjetividade se deseja para si.

\section{Referências:}

CASTRO, E. 2009. Vocabulário de Foucault. Belo Horizonte: Autêntica.

CAMARGOS, R. 2015. Rap e política: percepções da vida social brasileira. São Paulo: Boitempo.

CORLETT, J. Angelo. 2006. “'Para todos os meus pretos e vadias': ética e epítetos”. In: Hip hop e a filosofia: da rima à razão, p. 150 - 159. São Paulo: Madras.

FLEURY, M. C. 2015. “Hibridações locais e processos identitários: o rap em Goiânia e Aparecida de Goiânia". Dissertação de mestrado, Universidade Federal de Goiás.

GARCIA, A. 2014. “O rap entre mestiçagens e negritudes: música e identidade no Brasil e em Cuba (1988-2005)". Tese de doutorado, Universidade de Brasília.

GILROY, P. 2012. O Atlântico negro. São Paulo: Editora 34; Rio de Janeiro: Universidade Candido Mendes, Centro de Estudos Afro-Asiáticos.

GUERREIRO, G. 2010. Terceira diáspora: culturas negras no mundo atlântico. Salvador: Editora Corrupio.

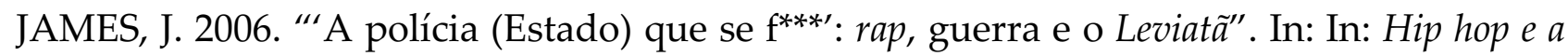
filosofia: da rima à razão, p. 76 - 86. São Paulo: Madras.

KELLY, E. I.2006. “Mentalidade orientada para o crime e a justiça: retribuição, castigo e autoridade". In: Hip hop e a filosofia: da rima à razão, p. 181 - 189. São Paulo: Madras.

LAWSON, Bill E. 2006. "Comandos do microfone: Rap e Filosofia política". In: Hip hop e a filosofia: da rima à razão, p. 161 - 171. São Paulo: Madras. 
MC PHERSON, Lionel K. 2006. "Revolução a meio caminho: daquele gangsta Hobbes aos liberais radicais". In: Hip hop e a filosofia: da rima à razão, p. 172 - 180. São Paulo: Madras.

OLÁRIA, V. 2012. Hip hop: arte-vida-trabalho e experiência docente. Goiânia: Editora UFG.

REVEL, J. 2005. Michel Foucault: conceitos essenciais. São Carlos: Claraluz.

ROSA, W. 2006. "Homem preto do gueto: um estudo sobre a masculinidade no rap brasileiro". Dissertação de mestrado, Universidade de Brasília.

ROSE, T. 1994. Black noise: rap music and black culture in contemporary America. Middletown: Wesleyan University Press.

SHUSTERMAN, Richard. 2006. "Estética rap: violência e a arte de ficar na real". In: Hip hop e a filosofia: da rima à razão, p. 66 - 75. São Paulo: Madras.

WACQUANT, L. 2008. As duas faces do gueto. São Paulo: Boitempo Editorial.

WEBB, G. 1998. Dark Alliance: the CIA, the Contras, and the crack cocaine explosion. New York: Seven Stories.

\section{FONTES DE PESQUISA:}

ARRAES, J. 2015. “Bárbara Sweet: 'Todas as mulheres do rap têm histórias de machismo pra contar"". Revista Fórum, http://www.revistaforum.com.br/2015/02/04/barbara-sweettodas-mulheres-rap-temhistorias-de-machismo-pra-contar/.

BLACK SOUL, F. 2009. "Afrika Bambaataa”. Blog. Felipe Black Soul, http://felipeblacksoul.blogspot.com.br/2009/06/afrika-bambaataa.html.

BOTELHO, G. 2010. Nos tempos da São Bento. Vídeo. https://www.youtube.com/watch?v=jtkND9L4IKQ.

FACÇÃO CENTRAL. 2007. Sei Que Os Porcos Querem Meu Caixão. Vídeo. https://www.youtube.com/watch?v=wmYKiRQnqbo.

FACE DA MORTE. 2011. Lado B Da Farda. Vídeo. https://www.youtube.com/watch?v=bJ0u8_ywg7c. .

GRIOT URBANO. 2015. \#5 - Elementos do Hip Hop. Vídeo. 
https://www.youtube.com/watch?v=VSHXBEdnXbk.

. 2016a. \#10 - O Hip Hop é uma Tecnologia!? Vídeo.

https://www.youtube.com/watch?v=2dkuHM2eK1I.

2016b. \#11 - Das Gangs às Crews Vídeo.

https://www.youtube.com/watch?v=3A-7eXNbgjg.

KRS-ONE. 2004a. Everybody rise. Texto. Genius.com. http://genius.com/Krs-oneeverybody-rise-lyrics.

. 2004b. Freestyle Ministry. Texto. Genius.com. http://genius.com/Krs-onefreestyle-ministry-server-verbals-lyrics.

. 2004c. One ilegal business Remix 2004. Texto. Genius.com. http://genius.com/Krsone-illegal-business-remix-2004-lyrics.

. 2004d. You go on? Texto. Genius.com. http://genius.com/Krs-one-you-gon-golyrics.

PARIS. 1990a. Escape from Babylon. Texto. Genius.com. http://genius.com/Paris-rapperescape-from-babylon-lyrics.

. 1990b. The Devil made me do it. Texto. Genius.com. http://genius.com/Paris-rapperthe-devil-made-me-do-it-lyrics.

RACIONAIS MC'S. 2007. A Vida é Desafio. Vídeo. https://www.youtube.com/watch?v=52NT9cSWC_8.

TESTEMUNHA OCULAR. 2013. Goiânia em Caos. Vídeo. https://www.youtube.com/watch?v=DotqEWPan_8.

. 2015. Frutos Da Rua (CD Completo 2002/Rap Goiano). Vídeo. https://www.youtube.com/watch?v=kOEkt9E4B44.

THIAGÃO E OS KAMIKAZES DO GUETO. 2009. Só Monstro. Vídeo. https://www.youtube.com/watch?v=mt_o-Aofu0E. 2012. Na fé de Deus - joga os plaquê. Vídeo.

https://www.youtube.com/watch?v=otzQONMROm8.

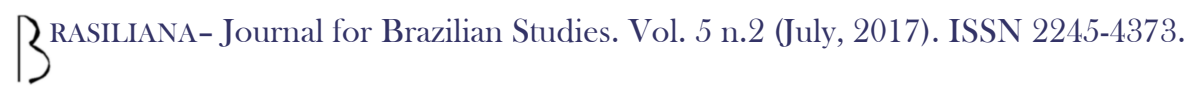

